\title{
Simulation of thermoset injection for bulk moulding compounds (BMC)
}

\begin{abstract}
This paper discusses about the simulation of the process of injection moulding for thermoset materials namely Bulk Moulding Compounds (BMC). BMC is a polyester resin based compound with glass fibre additives. In this paper a complex part was used to simulate and obtain the parameters for moulding BMC. Autodesk Moldflow Plastics Insight ${ }^{\circledR}$ was used to run the simulation. Two main parameters i.e. Injection time and mould temperature were considered. Six different sets of parameters were used and the settings were optimized. The obtained optimized settings are 15.08 seconds and $145^{\circ} \mathrm{C}$. The obtained parameters were then applied and the actual part was tested using an injection-moulding machine. After the simulation, changes were also made to the actual mould to improve the moulding conditions. Extra air vents were added at the problematic areas to ease the flow. There was an average variance of $7 \%$ which was thought to be acceptable as the simulation considers the ideal condition, where as there may be external factors such as the machine wear and tear during the actual moulding of the part. It can be said that the simulation was run successfully and tested during actual moulding.
\end{abstract}

Keyword: Bulk moulding compounds; Thermoset; Injection moulding; Autodesk Moldflow Plastics Insight ${ }^{\circledR}$ 